\title{
Getting men involved in family planning: Experiences from an innovative program
}

Directorate of Family Planning

National Institute of Population Research and Training

Population Council

Follow this and additional works at: https://knowledgecommons.popcouncil.org/departments_sbsr-rh

Part of the Health Communication Commons, Health Services Research Commons, and the International Public Health Commons

How does access to this work benefit you? Let us know!

\section{Recommended Citation}

Directorate of Family Planning, National Institute of Population Research and Training, and Population Council. 1997. "Getting men involved in family planning: Experiences from an innovative program," Asia and Near East OR/TA Project Final Report. Dhaka: Population Council. 


\title{
Getting Men Involved in Family Planning Experiences from an Innovative Program
}

\author{
Final Report
}

\author{
Directorate of Family Planning \\ National Institute of Population, Research and Training \\ (NIPORT) \\ $\&$ \\ Population Council
}

This project was supported by the Asia and the Near East Operations Research and Technical Assistance (ANE OR/TA) project of Population Council. The ANE OR/TA project is funded by the Office of Population, U. S. Agency for International Development (USAID), contract No. DPE C-00-90-0002-10.

Population Council

Dhaka, Bangladesh

April, 1998 


\section{CONTENTS}

List of Tables

III

List of Abbreviations

Acknowledgments $\quad$ V

Abstract

BACKGROUND 1

Rationale 2

Literature Review 3

$\begin{array}{ll}\text { OBJECTIVES } & 7\end{array}$

METHODOLOGY

Preparatory Phase $\quad 8$

Partnerships $\quad 8$

Formation of Technical Advisory Committee (TAC) 9

Selection of the Thana $\quad 9$

Design, Development and Pre-testing of Draft IEC Materials 9

Orientation Meetings with District and Thana-level Officers 10

Baseline Survey $\quad 10$

Focus Group Discussions with the FPIs $\quad 10$

KAP Survey 10

Situation Analysis (Needs Assessment) 10

Interventions $\quad 11$

Quarterly Participatory Workshop with Field Workers 11

12

National Workshop on Male Involvement

Printing and Distribution of IEC Materials $\quad 12$

$\begin{array}{lr}\text { Strengthening Supervision of MIP } & 12\end{array}$

NSV Training of the MO MCH-FP 12

$\begin{array}{lr}\text { Provision of Special Services } & 12\end{array}$

NSV Sessions 13

Male Hours in Selected FWCs 13

$\begin{array}{lr}\text { Interaction in the Monthly and Fortnightly Meeting } & 14 \\ \text { at the Thana and Union Level } & 14\end{array}$

$\begin{array}{ll}\text { Limitations of the Study } & 14\end{array}$

OUTCOME OF THE PROJECT AND EVALUATION

Findings from Process Evaluation $\quad 15$

Findings from Performance Evaluation $\quad 16$

Findings from Male Sessions $\quad 21$

$\begin{array}{ll}\text { Contacting of Males } & 21\end{array}$

Follow-up Survey of Condom Users $\quad 22$

Profile of NSV Clients $\quad 22$

Previous Contraception of NSV Acceptors 23

Findings from KAP Surveys $\quad 24$ 
References

Appendices

Appendix 1 Be A Responsible Father: Build UP A Happy Family

Appendix 2 Why the Involvement of Males is Important

Appendix 3 NSV: A Safe and Easy Method 


\section{List of Tables}

1. Union-wise Comparison of Condom Users, Kalihati Thana,

Page

1996 - 1997

17

2. Union-wise Comparison of New Condom Acceptors,

Kalihati Thana, 1996 - 1997

17

3. Union-wise Comparison of Vasectomy Performance,

Kalihati Thana, 1996 -1997

18

4. Center-wise Monthly NSV Performance, Kalihati Thana, 1997

19

5. Number of Contraceptive Acceptors by Methods, Kalihati Thana, $1996-1997$

6. Contraceptive Method Mix, Kalihati Thana, 1996 - 1997

20

7. Summary of Information About FWA Contact With Males by Union

21

8. Percent Distribution of NSV Acceptors and Their Wives

According to Socio-demographic Characteristics

23

9. Contraceptive History of NSV Acceptors by Duration

10. Percent Distribution of FWAs According to Visitation Status by Client Category

11. Methods Given Priority at the time of Home Visit

12. Workers Practices to Contact Husbands for Management of Side Effect 


\section{List of Abbreviations}

$\begin{array}{ll}\text { AIDS } & \text { Acquired Immune Deficiency Syndrome } \\ \text { ATFPO } & \text { Assistant Thana Family Planning Officer } \\ \text { AVSC } & \text { International Access to Voluntary and Safe Contraception } \\ \text { BDHS } & \text { Bangladesh Demographic and Health Survey } \\ \text { CPR } & \text { Contraceptive Prevalence Rate } \\ \text { CPS } & \text { Contraception Prevalence Survey } \\ \text { FGD } & \text { Focus Group Discussion } \\ \text { FP } & \text { Family Planning } \\ \text { FPAB } & \text { Family Planning Association of Bangladesh } \\ \text { FPI } & \text { Family Planning Inspector } \\ \text { FWA } & \text { Family Planning Assistant } \\ \text { FWC } & \text { Family Welfare Center } \\ \text { ICPD } & \text { International Conference on Population and Development } \\ \text { IEC } & \text { Information Education and Communication } \\ \text { IEM } & \text { Information Education and Motivation } \\ \text { KAP } & \text { Knowledge Attitude and Practice } \\ \text { MIP } & \text { Male Involvement Project } \\ \text { MIS } & \text { Management Information System } \\ \text { MO MCH-FP } & \text { Medical Officer Maternal and Child Health and Family Planning } \\ \text { NGO } & \text { Non Government Organization } \\ \text { NIPORT } & \text { National Institute of Population, Research and Training } \\ \text { NSV } & \text { No Scalpel Vasectomy } \\ \text { RTI } & \text { Reproductive Tract Infection } \\ \text { SACMO } & \text { Sub-assistant Community Medical Officer } \\ \text { SC } & \text { Satellite Clinic } \\ \text { STD } & \text { Sexually Transmitted Disease } \\ \text { TAC } & \text { Technical Advisory Committee } \\ \text { TFPO } & \text { Thana Family Planning Officer } \\ & \end{array}$




\section{Acknowledgments}

This project was supported by the ANE OR/TA project of Population Council. The ANE OR/TA project is funded by the Office of Population, U. S. Agency for International Development (USAID), contract No. DPE C-00-90-0002-10.

The authors would like to express their deepest gratitude to the Directorate of Family Planning and NIPORT for their initiation, guidance, co-operation and support of the project.

Special thanks are due to Mr. Sirajul Islam, Director General of Family Planning, for his extra ordinary co-operation, support and participation. His continued assistance contributed greatly to the fluidity and ultimate success of the project.

We would like to express our heartfelt thanks and gratitude to the Director General, NIPORT for his active support and guidance.

Dr. Ahmed Al-Sabir, Director Research, NIPORT and Mr. Tabibur Rahman, Director FP Dhaka Division also deserve thanks for their heartiest support of the project. The meticulous work involved in designing KAP survey questionnaire for the study was done by Mr. Subrata Kumar Bhadra of NIPORT. We would also like to acknowledge his efforts.

The authors would like to acknowledge the co-operation and initiatives taken by Mr. Alfazuddin Ahmed, DD-FP; Dr. Saidul Amin, ADCC; and Dr. Faria Hasin, MO-CC, Tangail. Special thanks are due to Dr. Mukbul Hossain, MO MCH-FP, Khandakar Saidur Rahman, TFPO and other supporting staffs at Kalihati Thana for their sincere co-operation and effort toward making the program a success. The authors would also like to express their sincere appreciation to all FWAs, FPIs, FWVs, SACMOs and other field staff of Kalihati Thana, for their contribution and active participation in the study. Special thanks to the FPIs and SACMOs of Ellenga, Narandia, Shahadevpur and Paikara for conducting male sessions. Deputy Commissioner, Tangail, TNO, Kalihati, Principal, MATS and FWVTI also deserve thanks for their contribution to the overall success of the project.

The authors would like to acknowledge Dr. Mizanur Rahman, Program Officer, Medical, AVSC International, for overseeing the quality of care and spending time on no-scalpel vasectomy (NSV) training for the MO MCH-FP of Kalihati Thana. The authors acknowledge the valuable contributions of Ms. Nancy Piet-Pelon, consultant, Population Council, for developing the IEC materials and reviewing the final report.

And last, but not least, the authors would like to acknowledge Mr. Dipak Shill, Office Manager, and Ms. Rahela Anam, Documentation Officer of Population Council for their administrative support and tedious hours of work they contributed toward making the workshop a success. The efforts of Mr. Mostak Ahmed, Mr. Abdul Majid, Mr. Nazimuddin Chowdhury, Mr. Abul Hossain, Mr. Sujan of Population Council are duly acknowledged. 


\section{Abstract}

The study was designed to determine the effect of several innovative interventions on accelerated proactive male involvement in family planning (FP) and programmatic factors influencing levels of acceptance of male contraceptive methods. This study, also referred to as the Male Involvement Project (MIP), was implemented by the Directorate of Family Planning and NIPORT with the technical assistance of Population Council in one thana of Tangail District, using the existing government infrastructure and manpower during the period between December 1996 and December 1997. It was observed that a program can be successful if management cadres can be motivated and involve in the process. Other findings suggested the importance of education and communication materials, supply of information, orientations of field workers, mobilization of resources including hands-on refresher training of MO MCH-FP on no-scalpel vasectomy (NSV) and supply of NSV sets at the thana level.

There were only two NSV operations done in the thana in 1996. This figure was not only raised to 71 in 1997, but condom use increased by 28 percent during the same period, due to MIP interventions. The prevalence of tubectomy has decline slowly in the study area during the past few years. That's why it was interesting to see the sharp rise in vasectomy during the intervention period. It can be safely presumed that this is a positive indication of male involvement in the FP program.

Information, Education and Communication (IEC) is not only an essential element of education and motivation among clients, but absolutely imperative as a tool for the service providers to portray the conceptualization of the program to prospective FP acceptors. The various IEC materials should contain messages about virility, explain appropriate contraceptive use and counter common misconceptions. Misconceptions about male contraception (particularly vasectomy) are rampant in traditional Bangladeshi society. Thus, ideas should be attractively pictorial through the use of visual aids, knowledge can be effectively transferred. Among the various IEC materials, at least one must be specifically for service providers.

Getting men involved in FP, the study recommended the importance, not only of motivation, but that efforts should be made to create a male-friendly service delivery system at the existing service delivery centers ( $\mathrm{H} \& \mathrm{FWCs}$ ). A series of orientation meetings were held at the various phases of the project, at which all officers and field workers were in attendance. These regular monthly meetings with all of the thanalevel FP workers were an excellent opportunity for in-depth discussions.

Vasectomy can be easily performed at the centers where there are adequate sterilization facilities. To satisfy the unmet need for vasectomy, NSV sessions should be organized regularly -- once or twice a month, based on local need. Specially scheduled hours should be set aside for the provision of information and services to men, from the Health and Family Welfare Centers (H \& FWCs) and at the community level. There will be a need to publicize these centers and times, so that men can easily obtain the FP information and services.

Family Welfare Assistants (FWAs) are quite capable of motivating males if they are properly oriented and equipped with effective IEC materials. It is encouraging to note that the FWAs, themselves, identified ways for male motivation. This study observed that the supportive supervision of male supervisors is essential in involving female FWAs in male motivation activities. 


\section{BACKGROUND}

The national family planning program of Bangladesh has made impressive progress in achieving a 49 percent contraceptive prevalence rate (CPR) and bringing the total fertility rate (TFR) down to 3.3 (BDHS, 1996-97). But there is still much to be done. If the national goal of reaching replacement-level fertility is to be achieved by 2005 , contraceptive prevalence has to increased 70 percent in the next five years. There is a need to identified innovative program interventions and that should be implemented with quality of care.

In the national program, a number of attempts have been made in the past to identify the critical issues that need to be addressed on a priority basis in order to further improve the program's performance. The National Steering Committee, in its Plan of Action for Future Challenges in the $\mathrm{FP} / \mathrm{MCH}$ program, identified ten immediate priority areas. Reaching under-served group, was identified as a critical first step. Men and newly-married couples comprised two under-served groups.

There are many good reasons to work more directly with men. In Bangladeshi society, men are considered to be the dominant members in any family decisionmaking process, including the decision to use FP methods. Therefore, greater involvement of males in FP is now a prime need. Male involvement in FP refers primarily to two distinct, yet inter-related programmatic goals. The first goal is to increase the use of male methods, and the support -- by males -- of female method use. And the second is to increase the involvement of men in FP decision-making with respect to method use.

There is now a growing consensus among program managers that increased male involvement is needed. The existing FP structure, however, has a strong female orientation. Both the deployment of a large number of female field workers at the community level and the use of female paramedics (FWVs) at H \& FWCs and Satellite Clinics (SCs), cater to the specific needs of women and children. Thus, the program is designed in such a way that it is easier for women than for men to get information and services. Historically, the value in soliciting involvement from and providing services to men has been largely overlooked.

Various studies have indicated that almost 15 percent of female clients discontinued their method of use because of their husbands' objections or unfavorable attitudes toward the method (CPS, 1991). Moreover, 5 to 14 percent of eligible female clients who intended to use FP methods, gave "objections/disapproval" of husbands as one of the reasons for non-use (BDHS, 1993-1994). Male sterilization accounts for a little over 1 percent and condom use is also very low at, 3.9 percent (BDHS, 1996-1997). Out of an overall contraceptive prevalence rate of 49 percent, the current use of methods by males is only 7.0 percent. This indicates a norm of method non-use among males, and may be a factor underlying the country's widespread unmet need.

Contacting male partners is not a priority for the FWAs during their home visits. The majority of them feel that it is inappropriate to talk to males about FP issues. They feel particularly uncomfortable explaining how to use male contraceptive methods. Moreover, it is the responsibility of the Family Planning Inspectors (FPIs) to contact and organize group meetings with males for motivation. Unfortunately this is not 
occurring. Another factor underlying the current programs bias toward females, is its emphasis on household distribution of resupply methods for women -- mainly the oral pill. Programmatic efforts should therefore develop appropriate strategies to initiate and sustain male involvement in FP method acceptance.

In a seminar sponsored by Population Council on male involvement in FP, the participants strongly advocated the need for concerted efforts to involve men more actively in the FP program. It was suggested that such an effort would help facilitate inter-spousal communication, and result in responsibility sharing for contraceptive acceptance and ultimately, an ideal family size.

Views of the husbands and wives on contraception often do not coincide. A better understanding of reproductive roles by men and joint decisions by couples could improve the effectiveness of FP program performance. The results of several studies indicate that increased use of contraceptive methods and continuation of female methods are higher when husbands are involved or a couple-focused approach is adopted for decision-making. Thus, there is a need to launch an intensive IEC campaign to sensitize and inform various segments of the male population about the importance of male involvement in FP.

This scenario calls for designing appropriate interventions and action plans for effective involvement of males and sustaining their participation in FP method acceptance-- especially for male methods. The present operations research project was developed and is being implemented to test the assumptions stated above.

\section{Rationale}

Why is male involvement necessary for the success of a FP program? In Bangladesh, the females have taken the bulk of the responsibility for FP-- as if they, alone were born and liable for procreation. Many studies have shown that females are more knowledgeable than men about FP issues and methods. This information gap however, poses as a barrier to contraceptive practices among wives, and is responsible, at least in part, for the relatively low participation of men in FP.

The success of the current approach of focusing all FP attention on women has reached a plateau; it is doubtful that it can achieve much more alone. Unwanted pregnancy continues, threatening women's health, despite the advent of oral contraceptives and the intra-uterine device (IUD) and in spite of the great amount of money and effort that have been invested in making women better contraceptors.

In the mean time, male involvement has been recognized as an important strategy toward the prevention of sexually transmitted diseases (STDs), including acquired immune deficiency syndrome (AIDS). One of the achievement of the International Conference on Population and Development (ICPD) was the recognition of the need to increase men's responsibility for their sexually and child rearing roles. Thus, bolstering male involvement is among the objectives of the Cairo conference's Program of Action.

As stated earlier, the current FP program caters to the needs of women. Nevertheless, many men believe that they should share fertility regulation responsibilities with their partners, but only a small proportion does so. The fact is, men face a very limited choice of contraceptive methods. NSV is the only new 
male method to be introduced in the last 25 years. Other methods available to men include condoms, coitus interruptus, and periodic abstinence that are all coitus dependent. The development of long acting, non-coitus-dependent, and reversible male contraceptive methods could fill the traditional method gap and be used to space births. Such methods are currently being researched and include injectable and implantable hormones, oral pill and vas occlusion (using silicon plug).

Despite the tardiness of modern male methods, those in existence are easy to use and almost free of side effects. Moreover, the condom has the tangible ability of preventing sexually transmitted diseases. This intervention will work toward promoting the existing male methods while it explores effectiveness of innovative approaches to getting men involved in FP. It will do so through the mobilization of existing resources.

\section{Literature Review}

Before launching the program, an extensive review of literature was done. This review of literature has identified several social, psychological and programmatic reasons for lower acceptance of male methods. It also identified some important issues which have discouraged males from actively participating in the $\mathrm{FP} / \mathrm{MCH}$ program.

The Family Planning Association of Kenya implemented a five-year project to encourage male involvement in reproductive health matters, including FP. The major interventions were an IEC campaign, support for male motivators at workplaces, and development of male reproductive health clinics, with a focus on male-friendly service delivery. The study showed that counseling, for men, largely entailed information gathering, while it served as a forum for decision making for women. Providers tended to give more technical, supportive, and detailed responses to men on FP methods, while ignoring and disagreeing more often with women. With men asking more detailed, sensitive, and difficult questions, they more often received inaccurate information compared to women (Kim et al., 1996).

Green et al. reviewed male involvement programs in more than 20 developing countries and recommend the following strategies to promote positive male involvement: i) changing the social norms which govern male behavior in sexual relations and parenthood; ii) incorporating male involvement in the overall planning of reproductive health programs; and iii) making service delivery programs more malefriendly specifically, they recommended the development of policies for making condoms and vasectomy more accessible; encouraging private-sector initiatives such as condom sales and workplace programs; giving more attention to specific male audiences -- especially youth; and promoting greater spousal communication (Green et al., Unpublished. 1996).

Karra et al. examined fertility decision making in South India, across five generations of one middle-class, high-caste Brahmin family from the state of Andhra Pradesh and the factors affecting its sudden fertility decline. Data were collected through interviews with 77 male and 101 female family members from the five generations. The authors concluded that traditional notions about gender roles and family, together with economic concerns, determines fertility decision making process. Moreover, individual motivation, rather than choice of methods played an important role in positive male participation in FP (Karra et al., 1997).

It is now understood that IEC materials play a major role in motivating clients 
towards FP. The IEC materials targeting exclusively males are limited in number. Findings from Philippines, suggest that IEC materials sustained male involvement in FP. The authors suggested that policy and legislation should support such involvement (David, 1996). A study on male involvement in Zimbabwe suggested that men could be reached with FP messages if appealing and appropriate communication channels are used and images of virility are incorporated into the messages (Kim et al., 1996; Marangwanda et al., 1996).

The choices of male methods are limited to withdrawal, condom, vasectomy and periodic abstinence. For the past decade, vasectomy has been least publicized contraceptive among all methods all over developing countries. Thus, misconceptions about the method are prevalent. Moreover, the present service provisions do not also adequately approach men to receive required services. In Pakistan, acceptance of vasectomy has been hindered by a lack of consistent government commitment, financial constraints, and socio-cultural factors. A survey of 1,354 married men revealed that 32 percent had heard of vasectomy, yet only 22 percent of these men could identify a source from where it can be obtained, and a mere 0.1 percent had accepted the method (Warriach, 1996). The study showed that, not only is there a view that Allah will determine family size, but that contraception is the woman's responsibility. Moreover, men and women share the fear that vasectomy will make men impotent and physically weak. The author also recommended that when vasectomy is first introduced to a community, involvement of the local leaders is essential and that until the government promotes vasectomy as an integral part of health services, overall success will be difficult to achieve.

Alexis, in his unpublished documents from a 1996 study, raised a very important points with regard to male involvement (Alexis, 1996). The author suggested that promotion of male involvement in reproductive health should not result in reduced commitments toward women's reproductive rights, gender equity, or equal status. The need to involve men in a comprehensive approach to reproductive health is now recognized, but the constraints to such involvement are less well known. Men know very little about human reproduction and sexuality. Moreover men fail to communicate about sex with their partners and men have strong beliefs in sexual myths, often blaming women for having only daughters or for being infertile. The introduction of FP as a woman's issue has made men suspicious of FP activities.

Barriers to male involvement in FP programs are also caused by service providers who assume that men have no interest in reproductive health (Alexis, 1996). Men are reluctant to seek medical treatment for conditions associated with social stigma (such as impotence and infertility). The author suggested that to promote male involvement, it should be understood that men make decisions about sex based on power, trust, and pleasure. Thus, programs should help men, understand the power which can come from promoting reproductive health. Also, programs must work toward overcoming the perception among males that acceptance of contraceptive methods is a threat to their status. Programs should also emphasize the pleasure to be derived from sexual intercourse. Outreach programs for men should use men as educators, promoters, and providers and should address a variety of topics.

Another study identifies reasons that why men have not been involved in FP. These includes fears among men about losing control; lack of political commitment; policy barriers (strict eligibility criteria for vasectomy); provider bias (programs oriented toward women); and inadequate information. According to Green well-targeted, malefocused programs can have a positive influence on both male and female reproductive 
health behaviors (more responsible sexual behavior, increased contraceptive use, and greater communication between partners) (Green et. al., 1995). The authors also recommended that male involvement activities should be integrated into overall program goals and strategies.

A number of authors emphasized counseling for patients undergoing sterilization and recommend counseling techniques for vasectomy acceptors to minimize the risk of litigation and post vasectomy regret. Providers of vasectomy services should conduct a personal consultation with the acceptors; discuss the impact of vasectomy upon sexual function; explain the procedure using diagrams at the time of physical examination; explain possible complications and risks, including the possibility of method failure; explain the need for a postoperative semen analysis and the need to use another contraceptive method for limited time after the procedure; emphasize the permanence of the procedure; have the patient read and sign an informed consent form; provide preoperative and postoperative instructions; and answer questions and respond to concerns (Haws et al., 1995).

Research on male involvement demonstrated that men are more likely to support FP and to use a method themselves if services and educational programs are targeted to them. Because men fear that contraception reduces their control over their wives' sexuality, male-friendly approaches can enhance gender equality in reproductive health decisions (Omuodo, 1996). In Togo, the media is being used to encourage positive attitudes toward FP among particular male groups. In Ghana, FP services targeted to men have resulted in increased male involvement. In Swaziland, male are targeted with FP education. In Sierra Leone, men have met in groups to learn about how to prevent sexually transmitted diseases and about the benefits of FP.

Conversely, by virtue of tradition and associated social factors, men in China have an active influence upon decisions about which method of contraception will be used in the family. Male involvement in FP, in the broad sense, is of considerable significance in China. The actual use of male contraceptive methods, however, varies widely by geographic area and culture. Study conducted on the extent and nature of male participation in FP in Sichuan, Yunnan, and Jilin provinces in 1992 suggested that, in Sichuan province 34 percent of all contraceptive acceptors relied upon male sterilization and 4 percent upon condom (Anonymous, 1995). The province has the highest rates of male contraceptive use in China. Strong leadership, complete information, and quality service were essential to achieving such a level of vasectomy acceptance in Sichuan. The absence of these factors in Jilin province explain why only less than 0.5 percent of contraceptive acceptors depend upon the permanent male method.

Use of terms such as "male responsibility," "male involvement," and "men's programs" when discussing reproductive health issues is contentious because the terms elicit varied interpretations and strong reactions. "Male responsibility" implies that men are irresponsible in character or are always irresponsible when they fail to use contraception. While "male involvement" connotes participation or engagement, some would argue that men are already too involved in reproductive health as policymakers, service providers, and husbands. The term "men's programs" is criticized because it suggests segregation of male and female services and creates a concept of male programs in opposition to female programs. It is proposed, therefore, that the term "men as partners" be used and that men's potential roles as partners in reproductive health be guided by their awareness of and support for the FP and reproductive health choices of their partners; their action to safeguard the reproductive health of their partners; their use of male contraceptive methods; and 
their cooperation with methods which require periodic abstinence (Verme, et al., 1995).

In Bangladesh, the FPIs (all males) who are primarily responsible for contacting and providing men with correct information on male methods and encouraging them to accept methods of their choice have not been performing their assigned responsibilities. The major emphasis through training and job orientation of the FWAs, has been directed at contacting the female partners of the couples and informing/educating them about contraceptives. Thus, they have not been advised of the importance of male involvement or encouraged to contact males by their supervisory officers (Population Council, 1997).

These findings, though not comprehensive, indicate that no concerted efforts -programmatic or otherwise -- were planned or organized to educate men on the importance of their role in FP. The existing educational approaches and programmatic efforts need to be reviewed and modified, so that both partners are reached. To ensure effective male participation in the FP program, it will be necessary to provide men with adequate information on FP and contraceptive methods through designing appropriate IEC materials. 


\section{OBJECTIVES}

The broad objectives of the project are to identify the programmatic factors influencing level of acceptance of male FP methods and to design and test appropriate strategies to accelerate proactive male involvement in the program.

The specific objectives are to:

- $\quad$ reduce misconceptions about the use of FP methods, especially condom and vasectomy, among men, through development and distribution of appropriate IEC materials;

- $\quad$ create a sense of responsibility among men to support their wives in their use of contraceptives and help them continue method use;

- create awareness among males toward responsible parenthood and sharing contraceptive responsibility;

- $\quad$ enhance interaction between field workers and male clients in order to increase knowledge on FP methods among males, and thus raise the acceptance rate of male contraceptives, especially vasectomy;

- assess the increase in contraceptive use among males attributable to the introduction of male-friendly clinic hours and programs; and

- increase the NSV acceptance among males-- particularly among couples wherein the wives are long-term users of spacing/resupply methods. 


\section{METHODOLOGY}

The study was conducted in four phases: preparatory phase, baseline survey, intervention phase and evaluation phase. This intervention study was conducted by the Directorate of Family Planning in their existing government system without providing any extra logistics, monetary or manpower efforts; but only mobilizing the existing resources. The program was implemented in the following ways.

- conduct situation analysis to assess: the attitude of service providers in providing FP services to the males; availability of service facilities and equipment; training needs, etc.;

- $\quad$ orient the front-line government and non-government field workers and service providers about the importance of male participation;

- $\quad$ design, develop and use appropriate IEC materials concerning different aspects of the program encouraging male participation and forming cooperative attitude between males and females and also between providers and the males;

- $\quad$ organize special hours in a fixed day for men to provide information and services on FP-MCH and other health-related issues from $\mathrm{H} \& \mathrm{FWCs}$.

\section{Preparatory Phase}

\section{Partnerships}

This project was a collaborative effort between the Directorate of Family Planning, National Institute of Population Research and Training (NIPORT) and the Population Council. It was assumed that such a collaboration would facilitate effective management of the program. Each individual organization's role was identified and responsibilities were divided. The Directorate of Family Planning was responsible for:

- $\quad$ selecting the thana to be used for the interventions

- $\quad$ ensuring that all officials were in position

- $\quad$ arranging orientation meetings with all of the concerned officials

- $\quad$ serving as a primary focal point for the interventions

NIPORT was responsible for:

- $\quad$ conducting the situation analysis in the selected thana

- $\quad$ assessing needs for training, particularly on NSV

- $\quad$ conducting the final evaluation of the project

Population Council was responsible for:

- $\quad$ technical assistance in the implementation of the project

- design, pre-test and print the IEC materials 
- $\quad$ arranging the master-trainer consultant for NSV training

- assisting NIPORT in conducting the situation analysis and conducting the training needs assessment

- $\quad$ report writing and dissemination of the findings

Formation of Technical Advisory Committee (TAC)

A technical advisory committee (TAC) was formed with the Director General, NIPORT and Director General, Family Planning as chairperson and co-chairperson, respectively. Members included Director IEM, Director Research, a representative from the Planning Cell of the Ministry of Health and Family Welfare, three representatives from Population Council, and a representative from NGO. The coordinator of the Male Involvement Project (MIP) was the member-secretary. The committee was responsible for providing guidance, ensuring proper implementation of the interventions and monitoring its performance. The committee met routinely during the implementation to monitor the project activities.

Selection of the Thana

Kalihati Thana of Tangail District was selected for the intervention. The total population of the thana was 395,311 in 1995. There are 12 unions in Kalihati. Each union has a population between 30,000 and 35,000. There were about 78,035 eligible couples in the thana (MIS report, 1996). Of these couples, government field workers provided services to 44,432. The remaining 33,603 couples were served by non government organization (NGO) workers. Kalihati was selected as the project area since it was the lowest performing thana of Tangail District. The CAR of the selected thana was 60.8 percent whereas the CAR in the highest performing thana was almost 70 percent.

\section{Design, Development and Pre-testing of IEC Materials}

Three different IEC materials were developed, pre-tested and printed (See Appendix 1). The pre-testing of the IEC materials was done through FWAs and FPIs. After pretesting, necessary corrections were done and the materials were printed. These IEC materials helped the field workers to improve their knowledge, while supporting their efforts during motivational activities. The IEC materials are:

- $\quad$ A brochure entitled "Responsible Parenthood," designed to highlight the role and responsibilities of men in FP. It contains the reasoning behind active participation of men in FP, outlines the role of men in the family, describes husband's responsibilities, discusses contraceptive decision making, and explains the disadvantages of frequent pregnancy on a women's health. These brochures were distributed among the community leaders and influentials of the area. It served as a visual aid for the FPIs and FWAs during the motivation of males.

- A brochure entitled "No Scalpel Vasectomy - Easy and Safe Procedure for Male," provides accurate and comprehensive information about vasectomy, and spells out the simplicity of the NSV operation. It was designed with the prime objective of dispelling misgivings and rumors about NSV. The brochure also gives an anatomical description of vasectomy, explains why males will prefer vasectomy, describes the eligibility for vasectomy, and lists the facilities where vasectomy is performed. The brochure was used by the field workers to 
motivate males to undergo sterilization and also by the clinical personnel for counseling prospective acceptors.

- A brochure entitled "Why Male Involvement in Family Planning is Necessary," has been developed for the service providers. This brochure served as a guide to the field workers. The brochure contains necessary information on the importance of male involvement in FP and outlines the motivational strategies to be followed for the interventions.

\section{Orientation Meetings with District and Thana level Officers}

Several orientation meetings were organized. The Deputy Director Family Planning, Thana Family Planning Officer, Assistant Thana Family Planning Officer (ATFPO), Medical Officer (MCH/FP), and Senior Family Welfare Visitor of Kalihati Thana participated these meetings. At these meetings, the district and thana-level officers were briefed about the importance and objectives of the project.

\section{Baseline Survey}

Focus Group Discussion (FGD) with the FPIs

A Focus group discussion (FGD) with 11 FPIs of Kalihati Thana was conducted by NIPORT, with technical assistance from Population Council. The FGD was organized to assess, the factors responsible for the low levels of male involvement in FP, and the low acceptance of male methods -- especially condom and vasectomy. It was also hoped that potential interventions for increasing participation of men and acceptance of male methods (specifically vasectomy) would be identified.

Knowledge, Attitude and Practice (KAP) Survey

Pre- and post-intervention surveys were conducted with 76 FWAs and FPIs by NIPORT and Population Council. The purpose of the surveys were to assess knowledge, attitudes and status of the motivational efforts undertaken for the male acceptors by the FPIs and FWAs and the barriers encountered in trying to involve males in the program.

\section{Situation Analysis or Needs Assessment}

A situation analysis, or needs assessment was conducted to assess: current attitudes among service providers in providing services to the males; the condition of the service facilities; and requirements with regard to equipment, training needs, etc. The above KAP survey gave an important indication of the needs of the service providers. Formal and informal discussions with the field workers, the supervisors and the thana managers were conducted. Moreover, visits were made to assess the requirements for instruments and other logistics. The organizational structure of FP activities is outlined below: 


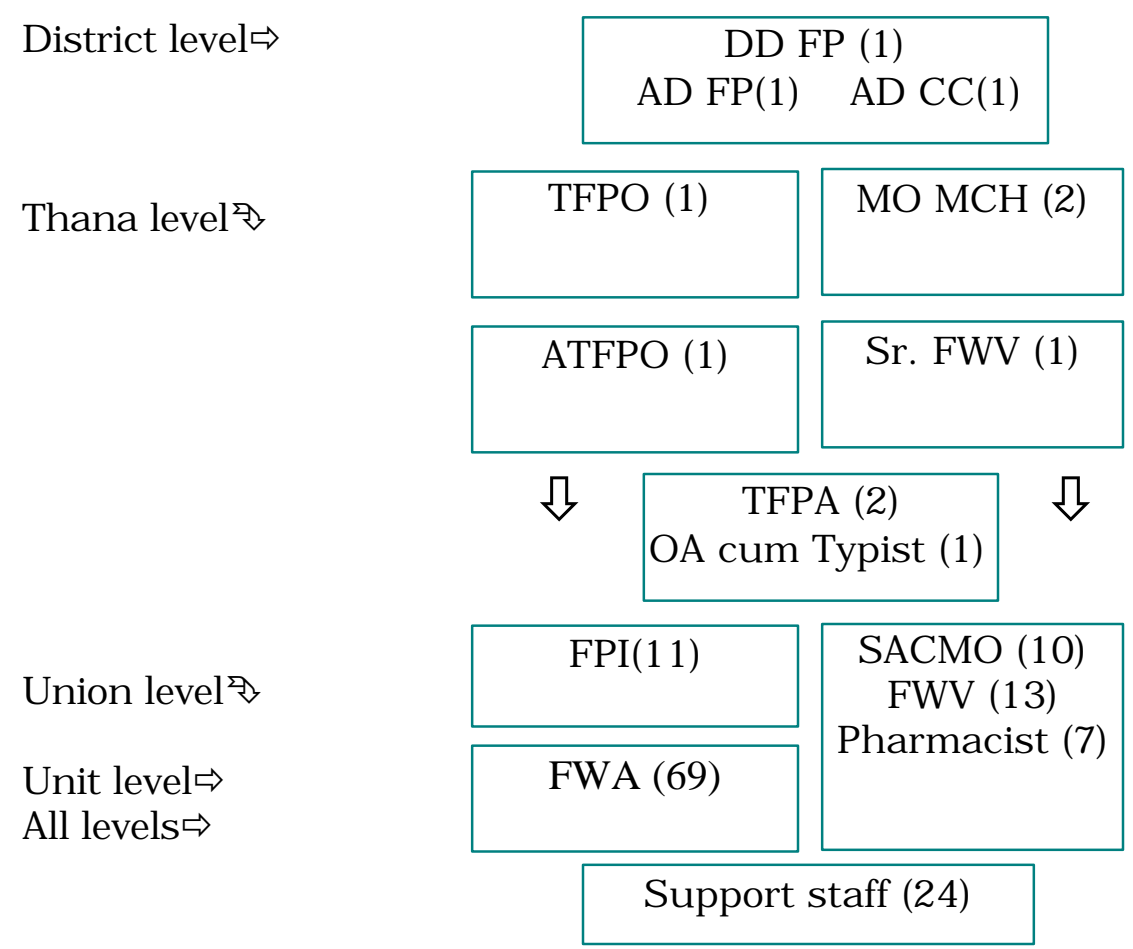

The total staff strength of the thana includes: five officers, 11 FPIs, 69 FWAs, 13 FWVS, 10 SACMOs and supporting staff. There are nine FWCs and eight health subcenters. In addition to these, regular SCs are organized in the project area. One medical officer (MCH-FP) was out of station for in-service training during the intervention period and one ATFPO and the Deputy Director (FP), Tangail, were transferred. A new DD-FP joined in the middle of the study period.

\section{Interventions}

\section{Quarterly Participatory Workshops with Field Workers}

Four orientation workshops were organized during the intervention period. All of the workshops were designed to achieve specific objectives. The first workshop was held at Ellenga and Kalihati and the subsequent three workshops were held at Tangail. The workshops were attended by the FWAs and FPIs of Kalihati Thana. The thana and district-level FP officials attended the workshop as resource persons. Population Council staff acted as facilitators.

The participants of the first workshop were divided into three groups and sessions were held separately. During the workshop, the FWAs and FPIs were briefed about the objectives of the project, interventions to be implemented and the role of the FWAs and FPIs in implementing the strategies. Discussions were held about the necessity of male involvement in the FP program and strategies for male. The draft IEC materials were distributed among the participants for feedback and suggestions. Out of the 69 FWAs, 66 were present. Director General of NIPORT, Director Administration and Thana Nirbahi Officer (TNO) Kalihati, attended the workshop.

The second workshop was designed mainly to address issues related to the newly developed IEC materials. At the workshop, the printed IEC materials were given to the participants with instructions about how to use them and to whom they were to be distributed. The prioritization of their educational efforts for males involvement 
were also discussed. DG-FP, DG NIPORT, Director FP Dhaka Division, Director Research NIPORT and DC Tangail attended the workshop.

The third workshop reviewed the activities of the field workers with regard to the use of the IEC materials. Program performance at each union was also reviewed and problems faced in the field were discussed.

The fourth and final workshop was organized to summarize the activities of the project and discuss the sustainability of the project. During the workshop, unionwise progress of male methods was reviewed. Program managers and field workers (FWAs and FPIs) of Kalihati Thana and representatives from the district FP office attended the workshop. FP officers from four other thanas (Sadar, Mirzapur, Shakhipur and Madhupur) also attended the workshop. They were invited by the DD-FP, Tangail with a view to acquaint them with the project activities for further replication in other thanas.

\section{National Workshop on Male Involvement}

In August 1997, a national workshop on male involvement was organized. Representatives from government, NGOs, donors and some of the field workers were invited to attend the workshop. Five other organizations were invited to share their experiences with the various aspects of male involvement. At the workshop, preliminary findings were presented and experiences were shared to further strengthen the project activities.

\section{Printing and Distribution of IEC Materials}

The printed IEC materials were distributed to the field workers at the second workshop. These IEC materials were subsequently distributed and used by the FWAs and FPIs as during their routine visits.

\section{Strengthening Supervision of MIP}

To ensure effective supervision for the implementation of the project activities, four FP managers were assigned to supervise and monitor the 12 unions of the thana. Each was responsible for between two and four unions. On their regular visits to the assigned unions, they reviewed the progress of the work, provided necessary guidance and helped to solve field problems. In addition, a supportive supervision model was put into practice which contributed to improvements in FP performance especially with regard to male involvement.

\section{NSV Training of the MO MCH-FP}

The need for training on NSV technique was identified at the beginning of project activities. To impart this training, a professional trainer from AVSC International was requested and refresher training was conducted at the field-level.

\section{Provision of Special Services}

The MIP introduced two types of special services into the community. These were NSV sessions and male hours at the FWCs. 
There are two sterilization centers in Kalihati Thana. One is at the Thana Health Complex at Kalihati, and the other is at Ellenga H\&FWC. Before the introduction of the project activity, only female sterilization was performed at these centers. During the project period, NSV service was offered from these centers. Arrangements were made with the Directorate of Family Planning for the procurement of the instruments necessary for NSV. Population Council facilitated the procurement process.

Usually, half-yearly sterilization schedule is prepared by the thana-level managers, in consultation with the field staff. This schedule was subsequently discussed and modified, if necessary, at the monthly meeting, held at the beginning of each month at the thana level. In the past, the field workers referred only tubectomy clients. After the introduction of project activities, field workers also started referring NSV clients. The field workers were supplied with IEC materials on NSV and ask to distribute these materials to potential clients and local opinion leaders. The medical officer MCH-FP perform NSV at the camp. The TFPO also attended these sessions to encourage field workers and resolve issues related to project activity. Four NSV sessions were scheduled every month on a fixed day of the week.

\section{Male Hours in Selected FWCs}

Regular sessions specifically for males were conducted during the second half of the project at four selected FWCs. These sessions organized once a week provided opportunities for men to receive FP information, especially on NSV, and common ailments. This was done to change the image of the FWCs, since they have always been known as female and child health care centers with no scope for men to receive information or services.

The selected FWCs displayed a billboard stating the time and day for male sessions, and describing the services available for men. A special attempt was made to involve couples -- both users and non-users-- and newlyweds in such orientation sessions. These orientation programs were organized and conducted by the FPIs and SACMOs in co-operation with the other clinic staff. The respective FWAs informed the couples -- especially the husbands -- about the male sessions during their field visits. Newlyweds, users of temporary method, acceptors who used contraceptive suffering from side effects, couples who have completed their desired family size and clients were identified as candidates for NSV and were encouraged to attend the sessions.

These sessions were also attended by thana and district-level managers and Population Council staff. Following topics were discussed in the these sessions.

- $\quad$ Family planning

- $\quad$ Complications and management of contraceptive side effects

- $\quad$ No-scalpel vasectomy (NSV)

- Responsible fatherhood

- $\quad$ Condom use

- $\quad$ Sexually transmitted diseases

- $\quad$ Reproductive tract infections

- Male participation in reproductive health decisions

These orientation meetings included discussions on a male's role in family formation, reproductive health, and the necessity for spousal communication in decision- 
making process. A special effort was made to influence the female partners of the couples to encourage and their husbands to use male methods. A register was maintained at the FWCs to record the number of males and couples attended, topics discussed, topics which generated more questions and person conducted the session.

\section{Interaction in the Monthly and Fortnightly Meeting at Thana and Union Levels}

At the thana level, meetings were held regularly at the beginning of each month to discuss programmatic and administrative issues. Thana-level program managers conducted the meeting. On several occasions, district-level managers attended these meetings. Regular monthly and fortnightly meetings were also held at the union levels to discuss issues related to the implementation of the program. Thana-level managers attended these meetings on a rotating basis and district-level managers sometimes attended these meetings. Representatives of Population Council attended both thana and union-levels meetings and exchanged views about the implementation of the program activities. Problems faced by the field workers were discussed at these meetings and necessary steps were taken to resolve the problems.

In order to motivate the workers, a sense of competition was created between the workers. Performance between and within unions was compared and reviewed and workers who had performed comparatively better were asked to describe how they were able to achieve such results. The frequent interaction between the field workers and the local program managers greatly enhanced the implementation of the program activities. District managers kept themselves up to date on the activities and issued directives to the field workers to further boost their performance. A letter issued by the DD-FP, Tangail, described the importance of male involvement program to attain replacement level fertility. It was also provided guidelines for workers to involve men in FP activities.

\section{Limitations of the Study}

The study had several limitations. First, there was no provision for a mass campaign at the community level for male involvement. Also, the impact of the IEC materials were not evaluated from the community or client levels.

The data were collected from the MIS report of Kalihati Thana. NGO performance data were not available for the year 1997 and as such, the statistics as shown are not quite complete. If the complete data had been available, a better performance comparison could have been done for the three years.

The study also suffered from a temporary slow down of activities, due to the transfer of key officials, whose role had been vital during the intervention period. There were also some vacant positions which created supervisory problems. All officers had to reoriented on project activities. Initially field staff, it expected additional financial incentives would be offered for performing project activities. When it was discovered that the project activities helped the personnel to perform their activities, the expectation of financial incentive was not present. 


\section{OUTCOME OF THE PROJECT AND EVALUATION}

The interventions began in February 1997 and continued until January 1998. During this period, planed interventions were implemented. Field staff implemented the project activities enthusiastically. Moreover, the project activities were performed by the Directorate of FP using their own resources and manpower.

\section{Findings from Process Evaluation}

The information collected during the pre-intervention phase helped to identify strategies for the project. Information about the level of male involvement and reasons for non-participation in FP activity was not collected at the individual level. The major findings from FGDs, situation analyses and field visits are as follows:

The majority of the FWAs discussed FP methods with female clients only. Two priority FP methods (tubectomy and oral pill) were emphasized during discussions with female clients. Husbands were left unattended and even overlooked in either information provision or motivational efforts about FP methods. Contact with males and their motivation in general -- and use of male methods in particular -- were not given due importance.

Most of the FWAs found that husbands were less interested and took less initiative than their wives both in the use contraceptives by themselves and in the encouragement of their wives to use contraceptive methods. In some cases, husbands extended no support to their wives when wives were suffering from sideeffects. Some husbands even created pressure on their wives to discontinue the particular method.

Many female clients who had been using temporary modern methods faced conflicts because their husband did not support their use of contraceptives. The field workers suggested that husbands and wives should be simultaneously contacted and motivated. They also advocated the importance of joint decisions (by both husband and wife) on the continued use of contraceptives.

The FWAs/FPIs recalled that they had not been informed at the time of training, refresher training or even supervisory visits, about the importance of male participation in FP. The IEC efforts in the past had been targeted primarily to females and failed to consider the opinion of males with regard to contraceptive decisionmaking.

Surprisingly, female partners were reported as barriers to the use of male contraceptive methods -- especially vasectomy. Wives fearing that a vasectomy would physically weaken their husbands, believed that it would result in more economic hardship to the family. Thus, it was necessary to re-educate the wives, who in turn, were able to play an active role in motivating their husbands to use male methods.

The situation analysis revealed the need to open service facilities for men in the existing infrastructure. The existing facilities could easily be used to deliver male services. These services, however, would need to be publicized. There was also an urgent need for NSV equipment. The equipment was procured through Family 
Planning Clinical Surveillance Team (FPCST). Much of the equipment and place used for tubectomy could also be used for male sterilization. The study also found that some minor but important instruments/materials were needed for quality services.

Training for medical officer MCH-FP on NSV and orientation meetings for the workers and officials was identified as an urgent need. In the absence of any IEC materials the service providers often felt helpless during their motivational work. The preintervention KAP survey uncovered important issues directly related to the service providers. Formal and informal discussions with field workers, the supervisor, and the thana manager were useful to identify special needs and logistics requirement.

The fourth workshop identified following steps to undertaken for future implementation:

- $\quad$ to organize meetings with newly vasectomized clients and motivate them to disseminate message in the community about the advantages of NSV.

- $\quad$ to organize a workshop with all FP workers and managers where a newly vasectomized client would be invited as a guest speaker to share his own experiences.

- to develop a definite detailed work plan for the activities related to male involvement.

- $\quad$ in order to increase male participation in FP, contact with male clients must be increased.

- $\quad$ to organize a workshop with all of the FP workers of Tangail District, to share the experiences of the MIP, so that it can be replicated throughout Tangail District.

- $\quad$ to supply newly developed IEC materials for the four remaining thanas of Tangail District.

- $\quad$ to arrange NSV training for the medical officer, $\mathrm{MCH}-\mathrm{FP}$ of the above four thanas.

- $\quad$ to further improve male sessions, the participants suggested that male group meetings should also be organized at the SCs.

- services and treatment facilities for males should be ensured from the FWCs.

- brochures, posters, flip-charts and flash-cards should be specially designed and printed for use at the male sessions.

- a workshop with newly-elected union parishad chairmen and members should be organized. Local opinion leaders should also be invited, to signify the importance of male involvement in FP.

Findings from Performance Evaluation

Quantitative information was also gathered to assess the impact of the intervention. The following table shows a comparison of condom users for the years 1996 and 1997. The quantitative data were collected from the MIS report of Kalihati Thana.

Table 1

Union-wise Comparison of Condom Users 
Kalihati Thana 1996 - 1997

\begin{tabular}{lcc}
\hline Union & December $\mathbf{1 9 9 6}$ & December $\mathbf{1 9 9 7}$ \\
\hline Durgapur & 175 & 256 \\
Salla & 179 & 272 \\
Ellenga & 193 & 299 \\
Narandia & 172 & 264 \\
Bangra & 147 & 279 \\
Kalihati & 185 & 298 \\
Shahadevpur & 133 & 214 \\
Paikara & 179 & 261 \\
Balla & 303 & 353 \\
Kokdahora & 162 & 262 \\
Birbashinda & 226 & 188 \\
Nagbari & 109 & 129 \\
\hline Total & $\mathbf{2 1 6 3}$ & $\mathbf{3 0 7 5}$ \\
\hline
\end{tabular}

Source: MIS Report, Kalihati Thana, 1997

The above table shows that the number of condom users increased from 2,163 in December 1996 to 3,075 in December 1997. The individual performance of all the unions increased, except Birbasinda Union.

Table 2

Union-wise Comparison of New Condom Acceptors

Kalihati Thana 1996 - 1997

\begin{tabular}{lcc}
\hline Union & $\mathbf{1 9 9 6}$ & $\mathbf{1 9 9 7}$ \\
\hline Durgapur & 88 & 145 \\
Salla & 45 & 184 \\
Ellenga & 83 & 165 \\
Narandia & 92 & 151 \\
Bangra & 74 & 171 \\
Kalihati & 80 & 124 \\
Shahadevpur & 80 & 179 \\
Paikara & 104 & 203 \\
Balla & 70 & 143 \\
Kokdahora & 76 & 154 \\
Birbashinda & 46 & 64 \\
Nagbari & 94 & 102 \\
Total & $\mathbf{9 3 2}$ & $\mathbf{1 7 2 4}$ \\
\hline
\end{tabular}

Source: MIS report, Kalihati thana, 1997

Table 2 shows that 1,724 new condom acceptors were recruited in the year 1997, as compared to only 932 during the previous year. The table also shows that there was an increase in the number of condom acceptors in all 12 unions of the Kalihati 
Thana. Other male methods, like withdrawal and periodic abstinence (rhythm) were not emphasized, since these methods are not as effective as condom or vasectomy. Table 3 shows that vasectomy performance has increased dramatically.

Table 3

Union-wise Comparison of Vasectomy Performance Kalihati Thana 1996-1997

\begin{tabular}{lcc}
\hline Union & $\mathbf{1 9 9 6}$ & $\mathbf{1 9 9 7}$ \\
\hline Durgapur & - & 2 \\
Salla & - & 12 \\
Ellenga & - & 13 \\
Narandia & - & 12 \\
Bangra & - & 1 \\
Kalihati & - & 2 \\
Shahadevpur & - & 6 \\
Paikara & - & 9 \\
Balla & 1 & 2 \\
Kokdahora & - & 2 \\
Birbashinda & - & 1 \\
Nagbari & 1 & 9 \\
Total & $\mathbf{2}$ & $\mathbf{7 1}$ \\
\hline
\end{tabular}

Source: MIS Report, Kalihati Thana, 1997

The above table shows that vasectomy performance in the year 1995 was nil and in year 1996, it was only two. But during the project period, vasectomy performance rose sharply from two to 71 . Out of these 71 vasectomy cases, 61 were performed at government facilities and the remaining 10 were performed at the FPAB clinic. During the field visits, the FWAs learned that 10 cases who came to FPAB clinic preferred it due to privacy. The following table shows monthly NSV performance during the MIP. 
Table 4

Center-wise Monthly NSV Performance

Khalihati Thana 1997

\begin{tabular}{lclll}
\hline Months & Kalihati & Ellenga & Others & Total \\
\hline March & - & 5 & - & 5 \\
April & - & - & - & - \\
May & - & - & - & - \\
June & - & 2 & - & 2 \\
July & 3 & 12 & 6 & 21 \\
August & 2 & 3 & - & 5 \\
September & 4 & 9 & 1 & 14 \\
October & 2 & 3 & 2 & 7 \\
November & 1 & 9 & 1 & 6 \\
December & 1 & 5 & - & $\mathbf{7 1}$ \\
\hline Total & $\mathbf{1 3}$ & $\mathbf{4 8}$ & $\mathbf{1 0}$ & \\
\hline
\end{tabular}

Source: MIS Report, Kalihati Thana, 1997

From the monthly report of vasectomized clients, it is clear that the highest number of cases performed occurred during the second quarter, followed by the third quarter. Performance during the initial three months was low. This was due to the low motivational level of the clients at the beginning of the project. As reported by FP workers, wives of potential vasectomy clients initially opposed the operation because they believed that their husbands would lose their ability to perform sexual act. After the project activities women began to realize the advantage of the NSV, performance began to increase. Of the 71 vasectomy operations, 13 were performed at Kalihati THC, 48 in Ellenga FWC and the rest at the FPAB clinic situated in Tangail.

Table 5

Number of Contraceptive Acceptor by Methods

Kalihati Thana 1996 - 1997

\begin{tabular}{lcc}
\hline Method & December $\mathbf{1 9 9 6}$ & December $\mathbf{1 9 9 7}$ \\
\hline Oral pill & 14055 & 15478 \\
Condom & 2163 & 3075 \\
Copper T & 745 & 829 \\
Injectable & 2455 & 2797 \\
Vasectomy & 389 & 455 \\
Tubectomy & 5300 & 5454 \\
Norplant & 236 & 215 \\
\hline Total & $\mathbf{2 5 , 3 4 3}$ & $\mathbf{2 8 , 3 0 3}$ \\
\hline
\end{tabular}

Source: MIS Report, Kalihati Thana, 1997

In 1996 the total number of contraceptive users was 25,343, and in 1997 it was 28,303 (Table 5). This indicates that contraceptive use has increased by more than 3,000 with the addition of 912 condom users. If we look at the individual method, all methods have increase in number in the year 1997 except Norplant. 
Table 6

Contraceptive Method Mix

Kalihati Thana 1996 -1997

\begin{tabular}{lcc}
\hline Methods & $\begin{array}{c}\mathbf{1 9 9 6} \\
\text { Percentage }\end{array}$ & $\begin{array}{c}\mathbf{1 9 9 7} \\
\text { Percentage }\end{array}$ \\
\hline Oral pill & 55.5 & 54.7 \\
Condom & 8.5 & 10.9 \\
Copper T & 2.9 & 2.9 \\
Injectable & 9.7 & 9.9 \\
Vasectomy & 1.5 & 1.6 \\
Tubectomy & 20.9 & 19.2 \\
Norplant & 0.9 & 0.8 \\
\hline Total & $\mathbf{1 0 0}$ & $\mathbf{1 0 0}$ \\
\hline $\mathbf{N}$ & $\mathbf{2 5 , 3 4 3}$ & $\mathbf{2 8 , 3 0 3}$ \\
\hline
\end{tabular}

Source: MIS Report, Kalihati Thana, 1997

Figure 1:

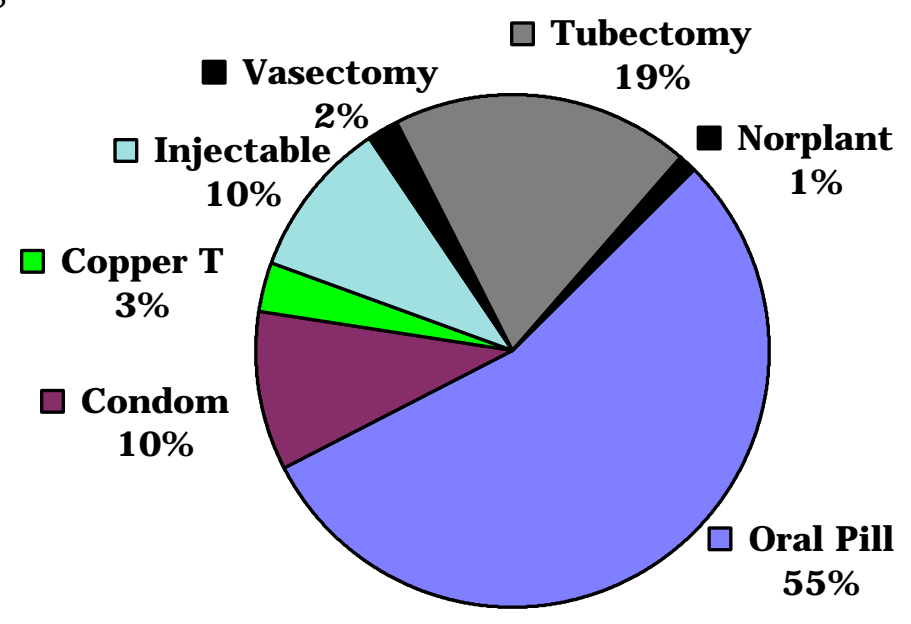

Methods Mix in the year 1997

Table 6 and figure 1 show contraceptive methods mix in the year 1996 - 1997 and 1997, respectively. Table 6 shows that the percentage of condom rise by 2.4 point (8.5\%-10.9\%) in 1997; reflecting a 28 percent increase in condom use. Whereas the percentage of vasectomy acceptors has been decling throughout the country, the decling trend not only stopped at Kalihati Thana, but began to reverse slightly by 0.1 percent $(1.5 \%-1.6 \%)$ in 1997. 
Information was collected from 28 male sessions, which were conducted at three FWCs. Between 5-7 men attended each session. On average, one couple was also present at each session. The FPI and SACMO were conducted the male sessions. During the sessions, males showed an interest on the following topics: NSV, STDs, condom use, RTIs and responsible fatherhood.

\section{Contacting of Males}

Males as well as females were targeted during the project intervention. Thus, it was necessary to monitor FWAs contact with males. A form to monitor male contact was developed and distributed to 30 FWAs of six unions of Kalihati Thana. Three months of performance data was collected and compiled. The data were then used to determine how many men the FWAs had contacted and how many were motivated to use condoms or undergo vasectomy operations.

Table 7

Summary of Information About FWA Contact With Males by Union

\begin{tabular}{|c|c|c|c|c|c|c|c|c|}
\hline \multirow[t]{2}{*}{ Union No } & \multirow[t]{2}{*}{ No of FWA } & \multicolumn{5}{|c|}{ Parity-wise number of males contacted } & \multicolumn{2}{|c|}{$\begin{array}{l}\text { No. of new } \\
\text { acceptors }\end{array}$} \\
\hline & & $\begin{array}{l}\text { Newly } \\
\text { weds }\end{array}$ & $\begin{array}{c}\text { No } \\
\text { children }\end{array}$ & $\begin{array}{c}1 \text { - } 2 \\
\text { hildren }\end{array}$ & $\begin{array}{c}\mathbf{3 +} \\
\text { children }\end{array}$ & Total co & Idom v & tomy \\
\hline Salla & 7 & 33 & 121 & 269 & 258 & 681 & 59 & 5 \\
\hline Ellenga & 3 & 20 & 83 & 188 & 291 & 582 & 20 & 1 \\
\hline Narandia & 6 & 64 & 99 & 237 & 301 & 701 & 17 & 1 \\
\hline Kalihati & 5 & 45 & 77 & 229 & 107 & 458 & 51 & - \\
\hline Paikara & 5 & 35 & 61 & 97 & 80 & 273 & 59 & 4 \\
\hline Kokdahora & 4 & 51 & 169 & 274 & 216 & 710 & 41 & 1 \\
\hline Total & 30 & 248 & 610 & 1294 & 1,235 & 3,405 & 247 & 12 \\
\hline
\end{tabular}

The above table (Table 7) shows that 30 FWAs contacted a total of 3,405 males, including 248 newlyweds during three months time period. The parity-wise distribution of contacted males is as follows: no child 858; 1-2 children 1,294; and 3 plus children 1,235. On average, 40 males were contacted every month by each FWA. In addition to this, all of the FWAs organized at least one male group session every month. As a result of these contacts, 247 males accepted condom as a method of contraception. Moreover, 12 males were vasectomized.

Follow-up Survey of Condom Users

A follow-up sample survey of condom users was conducted by the FPIs to examine satisfaction, dissatisfaction and the reasons for drop out among users. Thirteen clients were interviewed for this purpose. The average number of children for these 13 clients was 2.5. The survey showed that these clients had been using condoms for at least one year. Six of the clients had been using condoms for the last full year. Among the clients' wives, three had used the oral pill. The other had no history of contraceptive use. Four men mentioned that they use condoms because they have no 
side effects and can easily be obtained when needed. Three mentioned that they were using condoms to increase their sexual satisfaction. Another five mentioned that they used condoms purely for contraceptive purposes. None of the respondents mentioned use-related problems for condoms. All of the respondents expressed their intention to continue the use of method. All of the clients had received their condoms from the FWAs and were able to locate them at the time of survey.

\section{Profile of NSV Clients}

A post-NSV survey has conducted by FWAs for selected information such as age, education, occupation and parity (Table 8). Information on status and duration of previous contraceptive use was also collected. The survey indicates that the mean age of the NSV acceptors and his wife were 37 and slightly less than 30 years, respectively.

About 62 percent of the NSV clients had not attended formal school. In contrast, 84 percent of the wives had received no schooling. The data also indicate that husbands were more educated than wives (33\% Vs 12\%).

Day labor (daily labor, rickshawpuller, weaver, driver, etc.) was the most common occupation, representing 45 percent of the clients. One-third of the clients' occupation were related to agriculture, while one-sixth mentioned small business. One hundred percent of the wives were housewives.

Forty-five percent of the acceptors had three children and one-third of the acceptors had four or more children. Twenty-two percent of the acceptors had two children. Interestingly, the NSV acceptors had more male children than female children. 
Table 8

\section{Percent Distribution of NSV Acceptors and Their Wives According to Socio- demographic Characteristics}

\begin{tabular}{|c|c|c|}
\hline Category & Husband & Wife \\
\hline \multicolumn{3}{|l|}{ Age } \\
\hline Upto 25 yrs & 1.4 & 18.8 \\
\hline $26-35$ & 47.8 & 68.1 \\
\hline $36-45$ & 43.5 & 11.6 \\
\hline$>45$ & 7.2 & - \\
\hline Not Stated & - & 1.4 \\
\hline Mean Age & 37 & 30 \\
\hline Total & 100 & 100 \\
\hline \multicolumn{3}{|l|}{ Education } \\
\hline No Schooling & 62.3 & 84.0 \\
\hline $1-5$ yrs & 27.5 & 10.1 \\
\hline $6-9$ yrs & 4.3 & 1.4 \\
\hline 10 yrs \& above & 1.4 & - \\
\hline Not Stated & 4.4 & 4.4 \\
\hline Total & 100 & 100 \\
\hline \multicolumn{3}{|l|}{ Occupation } \\
\hline Agriculture & 33.3 & - \\
\hline Day Labor & 44.9 & - \\
\hline Small Business & 17.4 & - \\
\hline Housewife & - & 91.3 \\
\hline Not Stated & 4.4 & 8.7 \\
\hline Total & 100 & 100 \\
\hline \multicolumn{3}{|l|}{ Parity } \\
\hline Upto 2 Children & & 21.7 \\
\hline 3 Children & & 44.9 \\
\hline $4 \& 4+$ Children & & 33.4 \\
\hline Total & & 100 \\
\hline $\mathbf{N}$ & 69 & 69 \\
\hline
\end{tabular}

Previous Contraception of NSV Acceptors

The clients were asked about the status and duration contraceptive use. Of the 69 NSV clients, 52 had used some kind of temporary method before the operation. The majority of these were actually wives (18), who were using the oral contraceptive pill. Of the 52 temporary method users, 20 had used a temporary method (condom, oral pill, injection and copper T) for at least three years or more. Thirty-two of the clients had used the method for less than three years. Eleven of the 69 clients had used no contraceptive method prior to the NSV operation (Table 9). 
Table 9

Contraceptive History of NSV Acceptors by Duration

\begin{tabular}{|c|c|c|c|c|c|c|c|}
\hline Duration & Condom & Oral Pill & Injectable & Copper $\mathbf{T}_{\mathrm{I}}$ & $\begin{array}{c}\text { No } \\
\text { Metho }\end{array}$ & $\begin{array}{l}\text { Not } \\
\text { Stated }\end{array}$ & Total \\
\hline No Method & - & - & - & - & 11 & - & 11 \\
\hline$>1 \mathrm{y}$ & 3 & 4 & 1 & - & - & - & 8 \\
\hline $1-<3$ yrs & 2 & 18 & 3 & 1 & - & - & 24 \\
\hline $3-<5$ yrs & 1 & 10 & 1 & 1 & - & - & 13 \\
\hline $5 \&>5$ yrs & - & 6 & - & 1 & - & - & 7 \\
\hline Not stated & - & - & - & - & - & 6 & 6 \\
\hline Total & 6 & 38 & 5 & 3 & 11 & 6 & 69 \\
\hline
\end{tabular}

Findings from the KAP Surveys

Information was collected from FWAs and FPIs before and after the intervention. Comparison between the pre- and post-intervention home visits showed that less than 20 percent of the couples were contacted during home visits before the intervention. This figure had increased to about 50 percent by the end of the intervention (Table 10). No husbands were contacted independently (without their wives) by the field workers before or during the intervention.

Table 10

Percent Distribution of FWAs According to Visitation Status by Client Category

\begin{tabular}{lcc}
\hline Category & Pre-intervention & Post-intervention \\
& & \\
Wife only & 73.7 & 52.2 \\
Both & 18.4 & 47.8 \\
No information & 7.9 & - \\
\hline Total & $\mathbf{1 0 0}$ & $\mathbf{1 0 0}$ \\
\hline $\mathbf{N}$ & $\mathbf{7 6}$ & $\mathbf{6 9}$ \\
\hline
\end{tabular}

The FWAs were asked to name the two methods they gave highest priority during their interactions with clients, while making home visits (Table 11). Only 8 percent of FWAs mentioned vasectomy and 16 percent mentioned condom before the intervention started. After the interventions, these rose to 36 percent and 44 percent, respectively. The table below also indicates that FWAs have placed more emphasis on male methods after orientation workshop. 
Table 11

Methods Given Priority at the time of Home Visit

\begin{tabular}{lcc}
\hline Method & $\begin{array}{c}\text { Pre-intervention } \\
\text { Percentage }\end{array}$ & $\begin{array}{c}\text { Post-intervention } \\
\text { Percentage }\end{array}$ \\
\hline Tubectomy & 82.9 & 62.3 \\
Vasectomy & 7.9 & 36.2 \\
Copper-T & 19.7 & 7.2 \\
Injectables & 1.3 & 0.0 \\
Condom & 15.8 & 43.5 \\
Oral Pill & 67.1 & 50.7 \\
No information & 2.6 & 0.0 \\
\hline $\mathbf{N}$ & $\mathbf{7 6 *}$ & $\mathbf{6 9 *}$ \\
\hline
\end{tabular}

* multiple answer

Continuation of contraceptive use is related to a mutual decision (made by both husband and wife). There is a direct need of support from the husband to help in the management of contraceptive side effects and complications. The following table (Table 12) shows that prior to the intervention, only about one-fourth of the FWAs reported in more than 50 percent cases they contact with husbands for support if women suffer from contraceptive side effects. After intervention, 80 percent of the FWAs reported that they discussed with the husband for support in more than 50 percent cases if women suffer from any problems or complications due to use of contraceptive.

Table 12

Workers Practices to Contact Husbands for Management of Side Effect

\begin{tabular}{lcc}
\hline $\begin{array}{l}\text { Range of Contact } \\
\text { done with Husband }\end{array}$ & $\begin{array}{c}\text { Pre-intervention } \\
\text { Percentage }\end{array}$ & $\begin{array}{c}\text { Post-intervention } \\
\text { Percentage }\end{array}$ \\
\hline $1-10 \%$ & 34.2 & 1.4 \\
$11-20 \%$ & 19.7 & 2.7 \\
$21-30 \%$ & 2.6 & 0.0 \\
$31-40 \%$ & 9.2 & 0.0 \\
$41-50 \%$ & 10.5 & 15.9 \\
$>50 \%$ & 23.7 & 79.8 \\
\hline Total & $\mathbf{1 0 0}$ & $\mathbf{1 0 0}$ \\
\hline $\mathbf{N}$ & $\mathbf{7 6}$ & $\mathbf{6 9}$ \\
\hline
\end{tabular}

The FWAs and FPIs were asked whom they thought should be given importance for motivation to increase contraceptive use. Almost all (68 out of 69) replied that husbands and wives should be given equal importance.

In reply to the question, "Why is more male involvement necessary for FP?", the FWAs and FPIs gave a number of reasons: "men are the head of the family; male involvement 
will help to increase CPR; male methods are less time consuming, less hazardous, and have fewer side effects than females methods; male methods cause no difficulty during physical labor; and male methods allow men to share contraceptive responsibility." They felt that "through meeting with groups of males, collaborating with vasectomized clients, motivating males and motivating their wives" men can become involved in the FP program.

In reply to an another question, "what more can be done to involve men in FP?" the FWAs and FPIs suggested that: " supply of medicine should be improved; quality of lungi provided should be improved; motivation of local leaders should be done through satisfied vasectomized clients; support from opinion leaders, including union parishad chairmen, members, and imams should be solicited." The field workers also suggested that interpersonal motivational work and group meetings with males at the village level (with NSV clients) could enhance male participation in FP.

In reply to an another question, "what problems do you face during field visits: from males, from their wives, from yourself and from society as a female FP field worker?' Nearly fifty percent of the FP workers claimed that they faced some problems. The rest did not. Those who faced problems from males mentioned that "men are repeatedly unavailable during home visits." In respect to the NSV operation, it has been mentioned that they have counter misconceptions like "Will they be able to work hard? Will they be able to lift heavy things? Will sexual power be reduced? and will there be any problem during sexual intercourse."

Those FWAs who reported objections from wives mentioned that females were afraid of vasectomy because they believed that their husbands would not be able to work hard if vasectomized. The common reply was "shamikey kaasta na diyy nizayi kaasta kari" (I will bear troubles rather than my husband). Although there were no serious social or religious objections, discussions at the community level include, "omuker khashi karano hayysayy" (that person has been castrated). These type of stigma has a negative effect on potential NSV acceptors. 


\section{CONCLUSIONS}

Male involvement is not limited to male sterilization and condom use. It refers, rather, to the supportive attitudes that males have toward their wives and proactive sharing of responsibility in reproductive health matters, including contraception. Men are currently getting interest on FP activities.

The present study was implemented through the government infrastructure without recruiting any extra manpower. The most interesting finding was that improvement in program effectiveness could be achieved through mobilizing and efficiently utilizing existing resources already in place. Initiation of the process was the only outside role. This type of activity can be easily initiated at the community levels, by the concerned authorities. Other additional inputs include supply of IEC materials, orientation of field workers, mobilization of the resources, including hands-on refresher training of medical officer, MCH-FP and supply of NSV sets at thana level.

IEC materials were been distributed to the selected male groups which were, in turn, expected to help the field workers in their motivational efforts. The FPIs and FWAs made systematic efforts to reach men with specially designed IEC materials. The study observed significant impact of the various IEC materials developed by the project. The IEC pamphlet for the field workers, "Why is Male Involvement Necessary in Family Planing?" helped the field workers to conceptualize the program, understand the importance of male involvement in FP program and understand their role in the program. The brochure, "Responsible Father" has drawn renewed attention among males toward their responsibilities in fathering. The brochure, "No-scalpel Vasectomy - An Easy and Safe Procedure for Males", has helped potential NSV acceptors and field workers to have a clear understanding about male sterilization and helped them to remove misconception about the procedure. It also helped them to understand the advantages of vasectomy.

During 1995 there was not a single vasectomy case in the study area. There were only two cases of vasectomy in the year 1996. In the year 1997, however, 71 persons accepted vasectomy through the efforts of the MIP intervention. It can be safely presumed that this type of effort will contribute significantly to future program performance. In order to maintain momentum, it is necessary to reorient all field staff including officials with regard to the priority of the program.

Condom use was 8.5 percent in the year 1996. Due to the intervention, condom use increased to 10.9 percent in the study area. With regard to new condom acceptors, only 932 new condom acceptors were recruited during 1996. During the intervention period, however, this figure almost doubled $(1,724)$.

The study revealed that newlyweds accept contraception to postpone conception if they are properly motivated. Thus, newlyweds should be given special attention by the field workers.

Findings support that such an effort can be effective in increasing partnerships between husbands and wives in contraceptive use. It is possible to improve male involvement in FP, if this issue is handled tactfully and male partners are made to feel that their participation is important in the decision-making process for contraceptive 
use. Such decisions, however, should be made by the couple, rather than the individual. Communication between husbands and wives can play a major role in increasing male participation in FP. Future efforts to promote fertility regulation need to consider ways to counsel couples as a team and encourage inter-spousal communication in decision-making.

The study clearly shows that the existing FWAs are capable of being used to motivate males. It is encouraging to note that the FWAs found ways and settings in which they could talk with males. This was done through meetings at which both husband and wife were in attendance. In a strongly females oriented program the FWAs are not expected to talk with husband. It is observed that with adequate orientation and IEC materials, it is possible to use the FWAs to motivate and recruit vasectomy clients.

Supportive attitudes of the supervisors have an effective impact on male motivation. Now all of the FPIs are male. FPIs can take part in the program by arranging group meetings with males and can help the female FWAs to organize meetings at SCs with males.

The study cautiously examined the trend of FP acceptors of various other (beside condom and vasectomy) methods. Although the data are incomplete, an increasing trend is easily notable. Due to incomplete information, it was not possible to describe the exact trend, but it can be safely said that the efforts of the ongoing program activities did not lower contraceptive use rates in terms of the other methods.

All program personnel, from the thana level to the grass-roots level, have been given a renewed understanding about the importance of male participation in the FP program. As a result, a strong realization has developed -- especially among the FPIs and FWAs -- about the necessity for active participation among men in the FP/MCH program. This participation, it was found, not only increases CPR, but also helps to improve methods mix and improve quality of services.

The experiences from the Kalihati MIP showed that through male participation, acceptance of male methods can be accelerated. Furthermore, it demonstrated the importance of the supportive role of men in contraceptive use. If implemented nationwide, intervention could help the country to achieve replacement level fertility by the year 2005, while having the added benefit of preventing the spread of RTIs/STDs/AIDS by increase condom use. 


\section{POLICY RECOMMENDATIONS}

This intervention study came out with following policy recommendations:

- $\quad$ This intervention should be replicate nationwide. Additional inputs required would be limited to technical assistance, since the existing infrastructure can support the program activities.

- $\quad$ The study suggest that FWAs are quite capable to be used as a motivator for males. The study recommended to encourage FWAs to contact couples to review clients contraceptive option.

- $\quad$ Men should have specially scheduled hours to receive information and services at the FWCs and at the community level. Location of Health Centers from where men can receive information and health care services should be widely publicized. SACMO and FPI can manage the sessions.

- FWAs and FPIs should be properly equipped with IEC materials to motivate males as well as themselves.

- $\quad$ Orient all workers (community based, clinical and administrative) -- with regard to male involvement. The orientation sessions could be organized at any FWC or THC. Twenty five to 30 participants is an ideal size to stimulate participation and interaction. Moreover, orientation meetings should be held at the various phases. Issue related to male involvement, should be discussed at the regular monthly meetings to reinforce the objectives of the program.

- Vasectomy should be performed at the centers where adequate female sterilization facilities exist. Mobilization and utilization of the resources -- the refresher or basic hands-on training on NSV of the medical officers and arrangement for NSV sets -- should take place immediately. To satisfy the unmet need for vasectomy, NSV sessions should be organized regularly (once or twice a month), based on local needs. 


\section{References}

Alexis, E. 1996. Ensuring male responsibility in reproductive health. [Unpublished].

Anonymous. 1995. Who holds up half of heaven? Male involvement in family planning. Responses to ICPD. China Population Today 12(2):9-11.

David, F. 1996. Male involvement in family planning. In the Proceedings of the Operations Research Training Workshop: Mainstreaming NFP in the Public Sector, Manila.

Donahoe, D. 1996. Men and family planning in Bangladesh: A review of the literature, Population Council, Dhaka.

Green, C. P. and N. Danforth. 1996. Involving men in reproductive health: policy implications for developing countries [Unpublished]. Presented at the $124^{\text {th }}$ Annual Meeting of the American Public Health Association, New York.

Green, C. P., SI. Cohen, and H. Belhadj-El Ghouayel. 1995. Male involvement in reproductive health, including family planning and sexual health. United Nations Population Fund Technical Report 28, New York.

Haws, JM. and J. Feigin. 1995. Vasectomy counseling. American Family Physician 52(5): 1395-9.

Karra, MV., NN. Stark, and J. Wolf. 1997. Male involvement in family planning: a case study spanning five generations of a South Indian family. Studies In Family Planning 28(1):24-34.

Khuda, B., J. Helali, P. Miller, and J. Haga. 1994. Population Policy in Bangladesh: A review of ten priority areas. University Research Corporation (URC) and Population Council, Bangladesh.

Kim, YM. and D. Awasum. 1996. What are the particular aspects of counseling male family planning clients? Case from Kenya [Unpublished]. Presented at the 124th Annual Meeting of the American Public Health Association, New York.

Kim, YM., C. Marangwanda, and A. Kols. 1993-1994. Involving men in family planning: the Zimbabwe Male Motivation and Family Planning Method Expansion Project, Baltimore, Maryland, Johns Hopkins School of Public Health, Center for Communication Programs, 1996, IEC Field Report No. 3.

Mitra and Associates. 1991. Contraceptive Prevalence Survey (CPS), Dhaka.

NIPORT, Mitra and Associates, and Macro Internationals Inc. 1993-1994. Bangladesh Demographic and Health Survey, Dhaka.

NIPORT, Mitra and Associates, and Macro Internationals Inc. 1996-97. Bangladesh Demographic and Health Survey, Dhaka. 
Omuodo, DO. 1996. Africa takes a more male-friendly approach to family planning. AIDS Analysis Africa. 6(6):14.

Population Council. 1996. Male involvement: A challenge for the Bangladesh national family planning program. Policy Dialogue, No: 2, Dhaka.

Population Council. 1996. Regret after sterilization- can it be averted? Policy Dialogue, No. 4. Dhaka.

Population Council. 1997. Male involvement in family planning: Experiences from innovative projects. Workshop on Male Involvement, Dhaka.

Verme, CS., MN. Wegner, and T. Jerzowski. 1996. The language of male involvement: What do you mean by that? POPULI. 23(2):10-2.

Warriach, FA. 1996. Family planning methods for men in developing countries with special reference to vasectomy efforts in Pakistan [Unpublished]. 


\section{BE A RESPONSIBLE FATHER \\ BUILD UP A HAPPY FAMILY}

THE RESPONSIBLE FATHER

Directorate of Family Planning NIPORT

$\&$

Population Council

Appendix $1 \quad$ Page 1 


\section{A Small Family is a Planned Family}

For time immortal, men have left birthing issues up to women. Following the same line of reasoning many husbands think that it is the responsibility of the wife to practice FP methods in order to prevent conception or to have children at desired intervals. This line of reasoning is totally unfounded. Planning the appropriate number of children, according to capability to provide, and using contraceptive method should be processes, involving both the husband and the wife.

In our society, men often exercise more authority than women. This fact is reflected in family life. Most large decisions are made by males. The decision to have a small family is similarly dependent upon male judgment. Thus, in order to achieve measurable and sustained success in the FP program, the involvement of men will be a must.

We design schemes, more or less, for every aspect of family life. we calculate the correct to plant, arrange for future fruit production by planting trees around the house. We even plan the marriages of our children. But we are strangely indifferent and unmindful in deciding the number of children we should have, based on our socio-economic capability. As a result, unplanned family developed and an unplanned population explosion has occurred. This has created an undesirable situation in the family, manifesting economic adversity and the absence of adequate care for children. The most important responsibility of a father is not to increase the number of children, but to rear them up properly. The wife's role and contribution in this regard should not be go unnoticed. Because, the primary responsibility to bear as well as to rear children falls to her. It is therefore in the best interest of the family that a husband gives adequate support to the role of his wife, so that they can both be responsible for a small and well-managed family.

\section{A RESPONSIBLE FATHER IS NEEDED FOR BUILDING A SMALL FAMILY}

The liabilities of a responsible father are:

- $\quad$ to provide everyday food, clothing, medical attention and shelter for the family members.

- $\quad$ to educate the children properly to make them fitting citizens.

- $\quad$ to help establish a meaningful relationship with each family member.

A responsible father can determine how many children he will have in his family. In cooperation with his wife, he can:

- $\quad$ carefully plan and control the number of children in future.

- $\quad$ adopt a preferential method of contraception.

- $\quad$ plan for adequate spacing between children (at least 3 years)

\section{A MAN IS ALSO A RESPONSIBLE HUSBAND}

The role of a wife in the management of a family is undeniable. From dawn to dusk, in addition to rearing children, she also has to fulfill household responsibilities. She 
Appendix $1 \quad$ Page 2

is also responsible for bearing and birthing children. The sad fact of the matter is, we often cannot provide our wives with a balanced diet. Thus, most of them suffer from malnutrition, and which manifests itself as general ill health. The lives of these mothers become precarious if they bear children repeatedly under such conditions.

Most of us do not know that after giving birth to a child, it requires 2/3 years for a mother to regain the physical and mental strength necessary to bear and give birth to another child. In view of this fact, it is absolutely necessary for either the husband or the wife to practice a FP method, so that the wife does not get pregnant too often. Thus, the husband can either practice a method himself, or he can encourage and give necessary support to his wife if she is willing to adopt an FP method. In many cases where a couple does not want any more children and the women has been using the oral pill or injectable for a long period. It is most wise to adopt terminal methods. Although male and female methods are equally effective, male methods are simpler and safer than female methods. The major issue to be remembered is that the decision regarding the number of children a couple will have and which methods are most suitable, must be determine through communication between husband and wife.

\section{MALES AND FAMILY PLANNING}

The national FP program has come a long way in helping to educate millions of couples about how to build a small, but planned family and to have children at their own will. The field workers, through home visitation, made contact with couples -but especially females, in order to encourage them to have small families and select the best methods to suit their individual needs. There are, however, some weaknesses in the program. Among these is that the use of male methods is far less than that of the female methods. Of the total number of FP method users, only 10 percent are male. Not only are males refraining from contraceptive use, but many even influence their wives to discontinue use of a chosen method. It should be the joint responsibility of the husband and the wife to decide on the number of children they wish to have, based upon their economic efficacy. Then, they should practice the methods of choice. The family in which either the husband uses a male FP methods or he encourages and assists his wife in using use a method becomes a small family, in which happiness is bound to prevail. In our society, since men exercise more power in family matters than women, men should exercise their authority in building a small family.

\section{MALES NEED TO KNOW}

- that when a child is born, not only the wife, but the husband, as well, is responsible rearing and taking care of it.

- $\quad$ about the various FP methods available and how to use them.

- what kinds of problems can arise from using a chosen FP method, how to solve these problems and what a husband must do if such a problem arises.

- $\quad$ where to find the various FP. 


\section{Appendix 1 Page 3}

The decision to bear children should not be the sole decision of the husband. A wife's opinion should also be taken into consideration. Thus, husband and wife should act as a team in making major family decisions. This type of interspousal decisionmaking means that:

- discussions are held with the wife about any major family decision which will ultimately affect her life.

- the husband will, himself use a FP method, or

- $\quad$ the husband will help and co-operate with the wife to choose and use a FP method and help her to make it possible to continue method use.

- In case of side-effects, a husband should contact a field worker for remedial measures and, if necessary, take his wife to a clinic for treatment.

A responsible husband always helps his wife to plan the various important family activities. He must never lose sight of the importance of family planning.

"Either son or Daughter, two is enough"

..let this be our goal. 


\section{WHY THE \\ INVOLVEMENT OF MALES \\ IS IMPORTANT IN \\ FAMILY PLANNING}

Directorate of Family Planning NIPORT

\&

Population Council

Appendix $2 \quad$ Page 1 
The success of the national family planning/ $\mathrm{MCH}$ program in Bangladesh, is largely due to the efforts of the field workers. By dint of their efforts, and above all, their commitments have made it possible to raise the CPR from 7.7 percent in 1975 to 49 percent in 1996. This huge increase in contraceptive use is accompanied by a drop in fertility from 6.4 to 3.4 per women. Such success, however, should not be followed by complacency. If the national goal of establishing a two-child family standard is to be achieved by 2005, the CPR has to increase 70 percent. Accomplishing this difficult task will require the identification of key social and programmatic issues and adaptation of innovative program measures.

It is common knowledge that since 80 percent of all field workers are female, FP advise is largely distributed to the female partners. As a result, men receive little information from the program's efforts. There are many reasons for the lack of communication between the female field workers and male partners. Even the male FPIs, who are the main linkage to contact and motivate men through group meetings, do not play an active role in this endeavor, since they lack specified instruction to do so. Up until now importance has not been paced upon involving men. This has resulted in the following situation:

- $\quad$ Since specific attempts have not been made to motivate men, they are still misinformed about the advantages of a small family.

- $\quad$ Men have not yet been educated about the correct use of modern FP methods; their advantages and disadvantages.

- $\quad$ For lack of proper knowledge, many husbands (about $15 \%$ ) discourage or prevent their wives from using FP methods.

- $\quad$ Since motivation of husbands has not been given importance, the use of male methods is negligible in comparison to that of female methods. Moreover, the number of men using condoms or vasectomy is steadily decling.

Thus, the need to include males in the FP program is obvious. For this purpose, the following measures should be taken:

- $\quad$ Establish contact with husbands at a convenient time -- either individually or in groups.

- $\quad$ Provide husbands with necessary information/help so that they can become involved in planning with regard to the appropriate number of children to have.

- $\quad$ To provide precise information and consciousness to husbands on the various FP methods, how they help to prevent childbirth, techniques for using these methods, the advantages and disadvantages of using them and what to do when problems arise while using them.

- To inform husbands that for men, the use of the condom is very easy. Moreover, if one does not want children, vasectomy is also an easy and extremely safe process, and that prevailing rumors on vasectomy are unfounded. These husbands should also be provided with the information necessary to dispel these rumors. 


\section{Appendix 2 Page 2}

- $\quad$ To inform husbands of the advantages of having a small family -- instilling the idea that successful family planning will result in prosperous families, healthy wives, and financial integrity.

In our male-dominated society, men exercise the privilege of decision-making with regard to almost every family matter. This precedent should hold with regard to family planning practices. It is therefore imperative to undertake renewed steps to provide men with comprehensive knowledge on FP and motivate them to practice male methods. If we can motivate men to participate in FP:

- $\quad$ they will be more alert containing the number of children. Moreover, they will have the information necessary to accomplish this end.

- $\quad$ there will be an increase in the use of condom and vasectomy.

- they will motivate their wives to use FP methods, encouraging them to continue even if problems arise, and if necessary, will arrange for appropriate treatment.

- if a couple does not wish to have any more children and the wife does not prefers not to practice a long-term method, the husband may choose vasectomy.

- $\quad$ satisfied clients of male methods would play a leading role in encouraging other males to adopt male methods.

In rural areas, males and females rely heavily on FP field workers for FP/MCH- FP related information and services. Based on their advice, make the decision to use contraceptive methods. It is therefore, the foremost duty of the field workers to communicate with men in order to make them aware of their role in achieving a small family. 


\section{NSV: A SAFE AND EASY METHOD}

NO-SCALPEL VASECTOMY IS AN EASY AND SAFE METHOD FOR MEN IN FAMILY PLANNING

Directorate of Family Planning

NIPORT

$\&$

Population Council

Appendix $3 \quad$ Page 1 


\section{WHAT IS NSV (NO-SCALPEL VASECTOMY)}

This is one type of vasectomy where no scalpel is used for performing the operation. This is an easy, permanent method for men who decide they will not want any additional children.

\section{WHY SHOULD A MAN CHOOSE NSV?}

There are many advantages to NSV: With NSV,

- $\quad$ there is no incision needed.

- $\quad$ you need a small puncture instead of 1 or 2 incisions in the scrotum.

- $\quad$ there are no stitches needed.

- $\quad$ the procedure is quick and simple.

- you enjoy a rapid recovery.

- $\quad$ you experience little or no discomfort.

- bleeding or other complications are rare.

- ability to do hard work remains unchanged.

- $\quad$ sexual capability remains unchanged.

- $\quad$ you can be assured safety.

\section{IS NSV RIGHT FOR MEN?}

If you are absolutely sure that you do not want to have any additional children, and if you have two living children, you can have an NSV. It is a very easy method. It is best, however, to discuss the possibilities with your wife before making the final decision.

from the wide variety of family planning methods, you need to select the one which is best suitable suited to your needs. If you are young; if you have fewer than two children; if the age of your youngest child is less than two years; if you are not truly determined to take up NSV, then it is better for you to use the condom -- a short-term method.

\section{HOW DOES THE NSV WORK TO PREVENT PREGNANCY?}

A woman becomes pregnant when a male sperm unites with its female counterpart, the egg. During a sexual climax, the sperm of a sexually able man travels through the two tubes in his scrotum, mix with semen and travels up the vaginal canal to unite with the egg -- in resulting pregnancy.

While performing vasectomy, each of these sperm-tubes is tied by making a single puncture in the scrotum. As a result, the male sperm cannot unify with the egg. Without sperm in the semen, a wife cannot get pregnant -- even after having intercourse with her husband.

\section{WHY IS IT AN EASY OPERATION ?}

The NSV procedure is different from conventional vasectomy procedures. In it, instead of working through an incision in the sperm-tube, the tying of the tubes is done by making a small puncture. It is less painful because of the way the puncture is made. It is quicker because of the way the tubes are caught and tied. Instead of 
Appendix 3 Page 2

an incision, there is a only a tiny puncture. Moreover, an innovative, new method is used to grip the sperm-tube while it is being bound. The entire NSV takes only 10-15 minutes to perform.

After undergoing the NSV, you can return home immediately. within 2-3 days, you may also resume your normal daily chores. The operated area should be kept dry for 3-4 days as to prevent infection and to promote rapid healing.

\section{REMEMBER}

The NSV is not effective immediately. Even after the procedure, sperm which entered the tube prior to the operation may still in the tube. Following a vasectomy, after at least 20 ejaculations fear of sperm being in both the tubes is dissolved. Thus, after performing vasectomy, a condom or any other temporary method should be used at least for 15 ejaculations.

\section{WHERE CAN NSV BE PERFORMED?}

The Thana Health Complex and other selected FWCs/Clinics provide NSV services. If you want more information on this matter, contact the Family Welfare Assistant, Family Planning Inspector, Family Welfare Complex or Thana Health Complex of your area. They will be happy to serve you.

\section{SIDE-EFFECTS and COMPLICATIONS}

It is extremely rare to experience side-effects or complications from NSV. After the procedure is done, men retain their ability to work hard and experience sexual satisfaction.

You can return home right away just as the NSV is completed. Sexual relations are possible as soon as you feel comfortable.

Return to the clinic if you experience:

- $\quad$ fever during the first to fourth week after NSV.

- bleeding or pus in the wound.

- $\quad$ pain or swelling that does not stop.

\section{SOME MISCONCEPTIONS ABOUT NSV}

Reduction of Sexual Capacity and Enjoyment

- $\quad$ many people assume that after vasectomy, men loose their sexual powers. Some people think that after vasectomy, the sex-life of husband and wife is not pleasurable. these fears are unfounded.

- $\quad$ after vasectomy, sperm continues to accumulate in the testicles as usual and semen continues to secrete. The only difference is that the tubes has no longer conduct the sperm to the semen. Thus, male sperm cannot meet with the egg. 


\section{Appendix 3 Page 3}

Loss of Working Ability

- scientific findings have indicated that, there is no relationship between vasectomy and loss of working ability.

- $\quad$ any decrease in ability to work would be an emotional effect.

- $\quad$ wives of men who have undergone NSV have commented: "my husband has had a vasectomy, and has no problems. We are now very happy." 